\title{
AVATAR 1, MEDIA AND SOCIO-TECHNOLOGICAL IMAGINARIES: IMPLICATIONS FOR HCI RESEARCH
}

\author{
Jorun Børsting ${ }^{1}$, Alma Leora Culén ${ }^{1}$ and William Odom ${ }^{2}$ \\ ${ }^{1}$ University of Oslo, Oslo, Norway \\ ${ }^{2}$ Simon Fraser University, Surrey, Canada
}

\begin{abstract}
In this paper, we discuss the media coverage of a research product made for social innovation and its implications on our research and commercialization of the product that followed. We were interested in how media coverage shaped socio-technological imaginaries, cultural and social views of people around this new technology. The research product that was in the eye of the media interest was a networked artifact in the shape of a small robot called AV1, developed to reduce isolation among long-term ill children and adolescents. Discourse analysis was used to examine 170 news articles to explore diverse perspectives on AV1. Our work uncovers potential opportunities and challenges for researchers working with responsible social innovation and research products before commercialization. Further, it highlights the opportunities for research products to surface deeper entanglements between socio-cultural factors and technology innovation.
\end{abstract}

\section{KEYWORDS}

Research through Design, Research Products, Social Entrepreneurship, Socio-Technological Imaginaries, Media

\section{INTRODUCTION}

Social innovation has a strong focus on the social values of innovative products. Products that are the outcomes of design processes for social innovation are expected to mediate desired social values at scale. Often, the values are related to issues of social inclusion and bridging of social divides. For technology to mediate such values successfully and mitigate social challenges it tackles, it needs to have an impact on socio-technological ecologies. However, once an innovative technology is finished and launched as a commercial product, it is hard to make changes to the product that influence its implications for these ecologies. At the same time, before the product is broadly available, it is difficult to predict its social impact. The 'goodness' (positive impact) of social innovations is not a given (Godin, 2015), and issues around responsibilities for the ethical and social concerns related to such innovations arise (Stilgoe, Owen, \& Macnaghten, 2013). These challenges are not relevant for industries only, but also the academic research (Ribeiro, Smith, \& Millar, 2017).

With technology-based Social Entrepreneurship (SE) coming of age, it is timely to consider how academic research can recognize and pursue opportunities that collaboration with SE offers. SE seeks alternate ways to solve real-life social problems by combining technology, creative thinking and making, good social causes, values beyond profit, and different means of funding projects. It builds on social networking and use of social media for connecting, advertising, sharing, and crowdfunding. A research collaboration with SE introduces a set of opportunities and challenges for Human-Computer Interaction (HCI) research. In particular, since media engagement is an integral part of SE and essential for its success, academic HCI research can also get into the media spotlight. This paper discusses the implications of media and public interest in academic HCI research.

Heightened focus on social implications of design is evident in Interaction Design and HCI, where Research through Design (RtD) (Gaver, 2012; Höök et al., 2015; Pierce, 2014; Zimmerman \& Forlizzi, 2014), tangible, and ubiquitous computing (Ishii, 2008; Weiser, 1993) have been increasingly turning the outcomes of their research and design practice into innovative products. Researchers also turn their attention to implications for adoption of such outcomes, e.g., (Lindley, Coulton, \& Sturdee, 2017). Recently, in (Odom et al., 2016), the authors have articulated the concept of a research product through the practice of RtD. Research products, as described in their paper, have key interrelated qualities. They are research inquiry-driven, finished (in the sense that they represent the actuality of the design artefact, and not its potential, as is commonly the case with 
prototypes), independent (do not require the presence of the researcher to be used in the actual settings for which the product was intended), and fit (relates to the lived experience with the artifact, how it fits in everyday lives of those using it). Research products, thus, can be viewed as boundary objects between everyday life and research and design practice (see Figure 1a). They make it possible for researchers and designers to engage in inquiries on social implications and possible futures of commercial products. This opportunity extends a set of questions that can be asked beyond traditional studies, which rarely shift focus from developed prototypes of new technologies to socio-cultural entanglements that the product would be a part of, and into the realm of responsible design.

One of the long-term challenges of high relevance for responsible innovations is known as the Collingridge dilemma (Collingridge, 1980). The heart of this dilemma focuses on the questions of when and how to explore the consequences of new technologies. In the early stages of design and development, when changes to the design are easier to make, knowledge related to real-life experiences with the product is lacking. When the technology becomes a part of the socio-technological ecology as a commercial product, the social implications are more readily available, but it is often too late to make any design changes. In (Kudina \& Verbeek, 2018; van der Duin, 2018), the authors propose the concept of technology mediation as a way to address the dilemma, and build on the dynamics of the interactions between technologies and human values and inquiry into how technologies mediate perceptions, actions, and interpretations, and shape moral frameworks that affect moral actions, and decisions (Verbeek, 2011).

In this article, we position RtD and research products as a way to engage in field explorations as part of the collaboration with SE before product commercialization. The focus on commercialization of a research product is in contrast with previously published RtD research, where research products were not made toward commercialization, but for research purposes only, e.g. (Chatting et al., 2017; Odom et al., 2016). We draw on a particular set of experiences with a AV1 (stands for Avatar 1), see Figure 1b, and imageries created by the media with AV1 as a research product, and later, a commercial product (see Figure 1c - the commercial product has a more polished look).
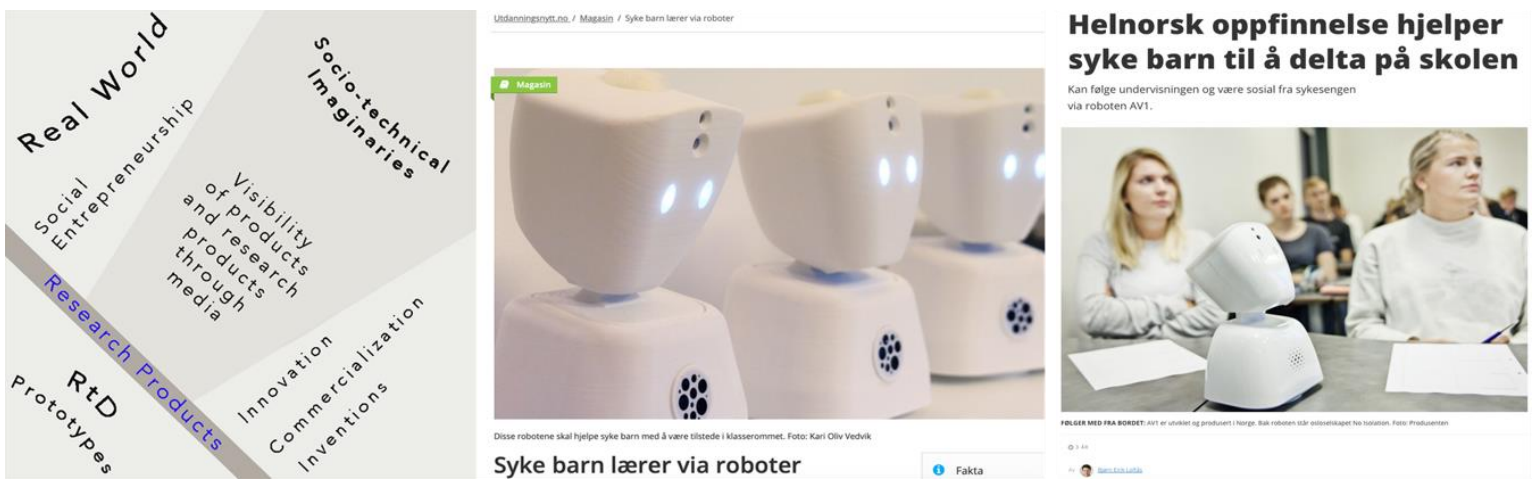

Figure 1. a) Research products as a boundary between the real world and the research b) AV1 as a research product used in this work - the headline reads "Sick children learn through robots" ${ }^{1}$ c) AV1 as a commercial product launched by No Isolation, the headline reads: "An entirely Norwegian invention helps sick children to take part in education" ${ }_{2}$

From the start of the collaboration with the SE startup No Isolation, the media attention has been massive. This was, in part, due to the importance of the underlying social cause that AV1 addresses - reducing isolation among children and youth who due to an illness cannot live an ordinary life. The fact that the research product was in actual use with seriously ill children, made our research more relatable to the media than the usual ways of dissemination of academic research and design, e.g., press releases, project websites or published articles. We collected both print and online media articles. However, for the purposes of this paper, we excluded social media and all advertisements and direct marketing by No Isolation. These have also had a huge impact, as they should in SE. However, we focus on the independent media coverage only.

The paper contributes to further understandings of how the media portrays HCI research. We argue that media discourse facilitates visibility of technological innovations, and in a case of social entrepreneurship and products such as AV1, opens for deeper public discussions and shaping of imaginaries. Our findings indicate

\footnotetext{
${ }^{1}$ In Norwegian, at https://www.utdanningsnytt.no/magasin/2016/juli/syke-barn-larer-via-roboter/

${ }^{2}$ At https://www.dinside.no/data/helnorsk-oppfinnelse-hjelper-syke-barn-til-a-delta-pa-skolen/61924788
} 
that although heavily outnumbered, critical opinions have had the most influence on the shaping of the product and on the business model, while the positive coverage had both positive and negative consequences for research, researchers and participants, strengthening sensitivities towards media engagement in HCI research.

\section{CONTEXT AND RELATED WORK}

To contextualize our research collaboration with No Isolation, we provide a brief background. Based on our prior research involving vulnerable children, we were approached by one of the startup founders, and asked to participate in their project with social relevance - to use technology to reduce social isolation among children and youth with long-term health challenges. They were to make a simple networked artefact, in the shape of a small robot. We took part in the process of turning this idea into a research product, carried out field work with it, and followed AV1's initial deployment as a commercial product. The collaboration period with No Isolation lasted approximately two years. After some months of development and planning for deployment, we received the first ten robots made and used them to inquire into fit in everyday lives of children with health challenges, including AV1's role in education (Børsting \& Culén, 2017) and social connectedness (Culén, Børsting, \& Odom, 2019). Research products, such as AV1, can challenge the existing social and cultural practices, as they are so new that there are no established regulations, conventions, or moral implications around them.

During the initial phase of the collaboration with SE startup No Isolation, AV1 existed as a research product only. Later, it was launched as a commercial product. This transition between non-commercial and commercial allowed for insights on how the public discourse changed. At that time, advertisements and video commercials in social media, movie theatres, city-wide digital displays, etc. became abundant, making AV1 into a familiar artefact nation-wide, something that everyone could have an opinion about. Thus, we chose discourse analysis to understand the socio-technological imaginaries and how people think, expect, and imagine the effects of technologies such as AV1 on the way we live. We focused on conceptions, images, stories, social expectations, and other notions shared by groups of people (Jasanoff \& Kim, 2015; Lockton \& Candy, 2018; Taylor, 2002).

Next, we present related work, divided into two themes: 1) previous work on RtD and the media and 2) commercialization of HCI inventions.

\subsection{RtD and the Media}

Media attention can enable researchers to communicate their research to local, national and international communities. Prior research that engaged the media often entailed writing press releases on a research project. Sometimes, research findings unexpectedly generated media attention (Vines et al., 2017, 2013). Regardless of the way in which the media gets engaged, researchers have been concerned that making their research public through media outlets can represent their work in skewed, interpreted or construed ways that are not in line with the expectations from the research community. Vines et al. (2013) describe such issues, but also argue that "misinterpretation could be considered useful as it provides a gauge for the political and emotional context of the work beyond the often homogenous, self-selected and motivated individuals that may participate in the research" (p.1879). The focus in our paper is somewhat similar, but extends to understand the social imaginaries created by the increased visibility of research products in the wild. The imaginaries open for inquiries into broader concerns regarding research product's positioning and entanglements with the socio-cultural context in the real world.

The design research project iFloor is an example of a research artefact that received a generous amount of media attention. Similar to AV1, it was seen by the members of the royal family (always a media attractor), reported to international audiences, and awarded prizes for being innovative (Koskinen, Zimmerman, Binder, Redström, \& Wensveen, 2011). The authors, however, do not address the implications of the media attention on the research, but highlight the importance of placing the research artefacts in the real world: "If designers participate in dialog about the meaning of their work, it is not only curators, critics, and media who define it. A degree of control can be gained this way" (ibid., p.98).

However, there are known accounts where media misrepresented research products and prototypes. For example, Auger's Audio Tooth Implant (Auger, 2013), a speculative prototype, has been described by Time Magazine as one of the best inventions of 2002. Other research artefacts misrepresented by the media as future commercial products include BinCam and Digital Cheques described in (Vines et al., 2013). In particular, 
Digital Cheques, a fictive product, was referred to by tabloid newspapers as 'Granny nav', causing public reactions regarding the offensiveness of the name given by the media.

As our research involves vulnerable user groups, we explored similar cases of research with vulnerable user groups and startup collaboration that gained media attention. In (Vines et al., 2017), the authors report that the media focus on their research with Google Glass as a self-care technology for people with Parkinson's made the participants express overly positive views regarding the technology, before actually using it. They highlight ethical dilemmas to consider when working with vulnerable users and the media. Another relevant example is the case of the Prayer Companion (Gaver et al., 2010), where reporters ${ }^{3}$ contacted the nuns who were using the research product (made to identify possible things that nuns could pray for). Although the nuns stated that they were ok with the media attention in this case, the attention conflicted with their monastic life and wows of seclusion.

In the case of our research, No Isolation generated media attention for marketing and fundraising purposes. The initial media focus on our research was a consequence of collaboration with No Isolation and forthcoming product commercialization. It was an unusual position. In line with other researchers who worked with the media, we recognized the importance of ethical concerns regarding the media coverage of AV1 and its users.

\subsection{Commercialization of HCI Inventions}

Concerns have been raised that great technology research innovations are too rarely developed into commercial products (Chilana, Ko, \& Wobbrock, 2015b; Isaacs et al., 1996). This concern is the driving force behind an increased focus on how to approach technology exchange of research innovations to successful commercial products (Chilana et al., 2015a). Adoption-centered design and implications for adoption are examples of approaches that connect research innovations to commercialization. Adoption-centered design (Chilana et al., 2015b) focuses on a process of building an understanding of, and designing for, adopters and stakeholders of the product. The approach usually utilizes in-depth case studies of how a particular technological research innovation transitions into a commercial product, e.g., LemonAid, peer-to-peer help tool called that evolved into a startup from a research project or AnswerDash that lets users find precise answers quickly on websites, financed by venture capital and serving as a hybrid between the academic research and entrepreneurship. Implications for adoption (Lindley et al., 2017) highlights the role of DIY (Do-It-Yourself) and maker movements (Grimme, Bardzell, \& Bardzell, 2014; Ratto, 2011; Tanenbaum, Williams, Desjardins, \& Tanenbaum, 2013), and advocates the use of design fiction as world-building to form speculations related to research innovations to scrutinize and explore the implications and requirements associated with a research-to-product transition in the future.

\section{METHODOLOGY}

We choose discourse analysis as the analytical tool of media coverage of AV1. Discourse analysis is a research method that provides systematic evidence about social processes by examination of speech, writing and other forms of communication in the media (Talja, 1999; Wortham \& Reyes, 2015). While common in social sciences, discourse analysis is not used that frequently within other research fields. In part, because it does not aim to capture participants' intentions, needs, meanings, or experiences, but cultural and social understandings. As mentioned in the introduction, we aim to uncover socio-technological imaginaries regarding AV1 as a new technology that made the presence of robots in everyday lives very concrete for the Norwegian population.

\subsection{Discourse Analysis}

The basis for the analysis, as shown in Table 1, were 170 media articles published during our collaboration with No Isolation, and separated into the first year when AV1 was a research product, and the second year when it became commercial. The articles examined, appeared in local newspapers, national and international newspapers, magazines and books, and online coverage of conferences or other arrangements (such as the Oslo Innovation week, technology fairs, concerts, TV-shows, etc.) where AV1 was featured. The articles were then

\footnotetext{
${ }^{3}$ At https://www.yorkpress.co.uk/news/8265632.nuns-of-poor-clares-in-york-embrace-technology-to-help-them-pray/
} 
divided into four main a-priory decided on categories: positive discourse (technology positivism, but also other positive attitudes), neutral (descriptive and factual), balanced (reflecting on both positive and negative implications of the new technology, even if the coverage was not equal), and negative coverage, see Table 2.

Table 1. Types of Media Coverage

\begin{tabular}{lcccc}
\hline Coverage of AVI & Local News & National/International & Magazine/Book & $\begin{array}{c}\text { Conference/Social } \\
\text { events }\end{array}$ \\
\hline Year 1 & 4 & $29 / 1$ & $12 / 2$ & $11 / 3$ \\
\hline Year 2 & 11 & $30 / 26$ & $12 / 0$ & $27 / 2$ \\
\hline Total: & 15 & 86 & 26 & 43 \\
\hline
\end{tabular}

Table 2. Discourse Analysis Results

\begin{tabular}{lcccc}
\hline Coverage of AVI & Positive & Neutral & Balanced & Negative \\
\hline Year 1 & 61 & 0 & 1 & 0 \\
\hline Year 2 & 102 & 0 & 3 & 3 \\
\hline Total: & 163 & 0 & 4 & 3 \\
\hline
\end{tabular}

Table 2 shows that AV1 was never described purely in terms of facts, or in a neutral language. It also shows a clear prevalence of positive attitude towards this new technology (163 articles). Most coverage, especially during the first year, focused on how AV1 could mitigate long-term negative effects of being ill in regards to education, or wellbeing, see Figure 2. The second year, after the commercialization, sees a slight increase in balanced and negative coverage, but still, a huge majority of positive articles.

Within the positive category, the discourse followed technology positivist way of telling the story, social positivism or it portrayed positive experiences with the research product in use. We exemplify these in turn: "The robot can make the everyday life better for cancer-affected, ME-sick or others who for various reasons must be away from school over time", "Seriously ill children are often isolated from school and friends. A new robot changes that now" (technology positivist view, where the robot changes the situation), "Children affected by serious illness often have to live their lives either at home or in the hospital. It can be difficult to participate in leisure activities, birthdays, or just attend school. But now five Norwegian entrepreneurs have spent four months developing something that gives hope, which can change these children's lives completely", "for the sick children and their families, it is usually not the illness that is experienced as the worst. It is the social isolation and absence from friends, classrooms and everyday events that is the hardest", "The reason why we have invested in No Isolation is that they want to contribute positively to the world" (social positivist view where the robot is replaced by 'something that gives hope' and the focus is on entrepreneurs changing people's lives), “... is looking forward to have his own robot that he can send to the school to keep in touch with his friends - It will be very nice. It's a fantastic invention, the ten-year-old smiles", "A robot that can be in the classroom changed the lives of many users. Emil in the ninth grade says: "Thanks to the robot, I have been able to attend more school in a week than the whole year combined. And, I've been with my friends" (positive experiences from robot users).

Examples of discourse categorized as negative reject the idea of the robot being the replacement for people "I am only saddened by the advertisements showing children carrying the robot instead of the classmate being there with them. I think it will contribute to a more intense feeling of loneliness", or express concerns with privacy "I find it worrisome that the outside world should have a peephole into where students are learning and failing, being educated and shaped". An example categorized as balanced "The robots are cherished for the opportunities they give sick children to participate in teaching and social contexts, but they are not necessarily unproblematic in use" try to point out both positive and negative issues regarding the topic.

We discuss next the imaginaries regarding connectedness, SE and gender, critical voices and governance. 

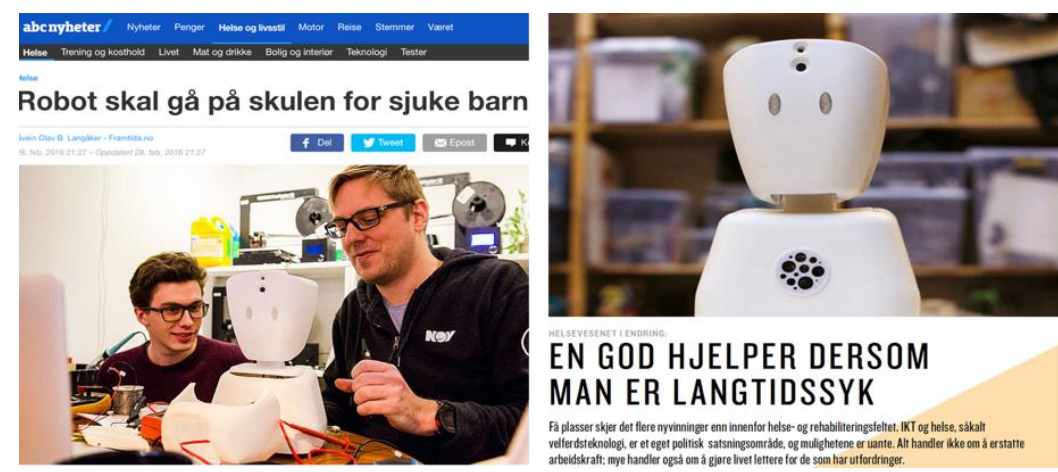

EN GOD HJELPER DERSOM

MAN ER LANGTIDSSYK

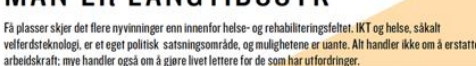

Ny teknologisk virkelighet for kreftpasienter

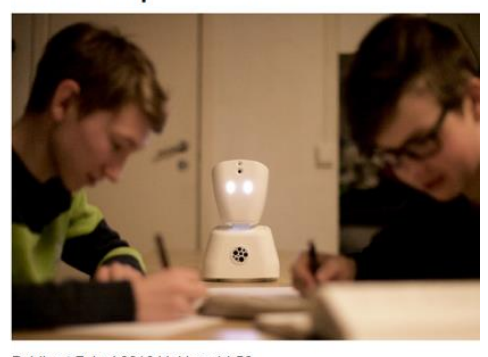

Figure 2. The figure points to divisions concerning AV1: is it an educational help or an artefact that reduces isolation and improves the quality of life for sick children? a) In "Robot going to school for sick children" 4 AV1 is about education. b) In "A good helper if one is long-term ill"5 and c) "New technological reality for cancer patients" 6 AV1 is about wellbeing

\subsection{Imaginaries}

\subsubsection{Social Connectedness}

Many articles discussed how chronically, or long-term ill children and youth can now be socially connected: "This robot can save children with long-term illness from loneliness" "7 or "Robot breaks the isolation", Figure 3a. In this imaginary, technology is a powerful weapon capable of reducing isolation. To bring forward these powerful images and expectations related to the 'new connected reality', the media often uses individual stories. Among articles that addressed connectedness, nine were written at the start of our research and featured participants in our research (unsolicited by researchers) with youth with ME (Myalgic Encephalomyelitis). Children and adolescents with other illness at risk of isolation, such as cancer, were also portrayed in articles.

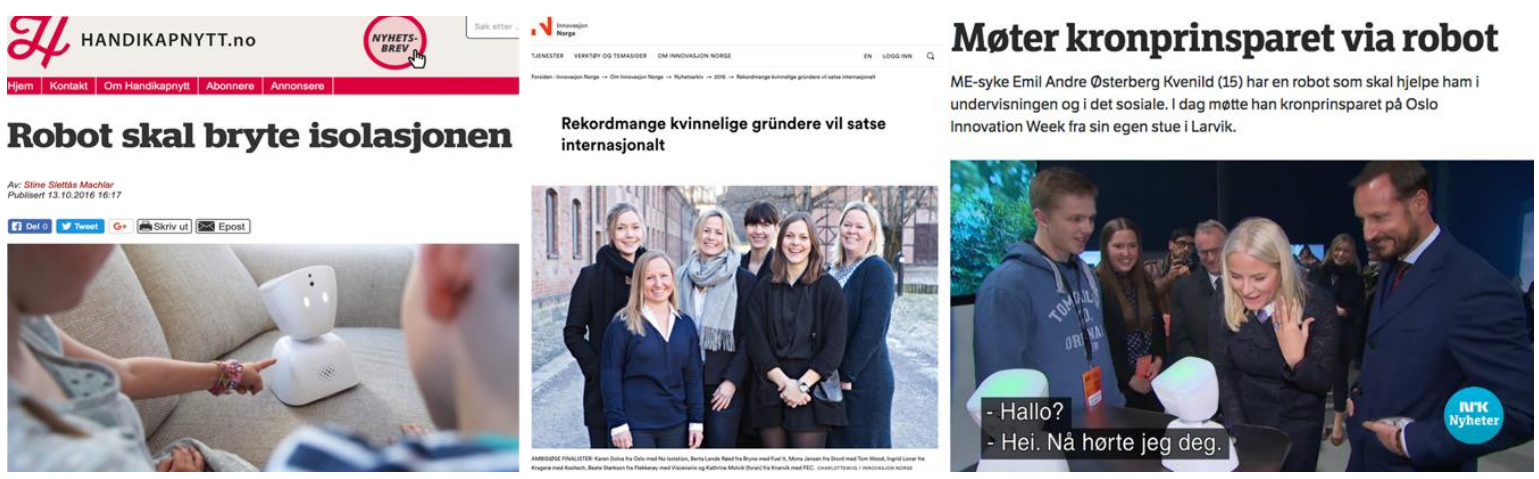

Figure 3. a) News article "Robot breaks the isolation", b) Innovation Norway's article "Record numbers of female entrepreneurs will invest internationally", , c) Norway's Crown Princess trying AV1 robot at Oslo innovation week ${ }^{10}$

\subsubsection{Gender and Social Entrepreneurship}

When No Isolation was founded, the oil prices were falling and the unemployment numbers raising. Subsequently, many of the published articles focused on social entrepreneurship. The articles in this group told the public about No Isolation founders, or opportunities for startups that opened with the growing DIY and maker movements, see Figure 2a, daring to take a leap into social innovation with products like AV1.

\footnotetext{
${ }^{4}$ Available (in Norwegian) at https://framtida.no/2016/02/27/robot-skal-ga-pa-skulen-for-sjuke-barn

${ }^{5}$ At https://samfunnsviteren.no/2017/06/07/en-god-hjelper-dersom-man-er-langtidssyk/

${ }^{6}$ At https://ungkreft.no/blog/2016/06/07/ny-teknologisk-virkelighet-for-kreftpasienter/

${ }^{7}$ At http://www.frambu.no/Article1 .aspx?NodeId=DFF8DCEF-A3CB-4F12-B192-1ED61D112912

${ }^{8}$ At https://www.handikapnytt.no/robot-skal-bryte-isolasjonen/

${ }_{9}^{9}$ At https://www.innovasjonnorge.no/no/om/nyheter/2016/rekordmange-norske-grunderkvinner-vil-satse-internasjonalt/

${ }^{10}$ At https://www.nrk.no/vestfold/moter-kronprinsparet-via-robot-1.13182768
} 
A large media attractor was the fact that one of the No Isolation founders was female. She was one of the finalists for the Female Entrepreneur award in 2016, and as such, featured in several articles. She represented the image of a young, creative women in mid-twenties, with stories that include other startups already behind her, and other social entrepreneurship projects in front of her (reducing isolation among elderly, as one example). Among these, one article talked about female entrepreneurs investing abroad, see Figure 3b, featuring the female CEO from No Isolation.

In October 2016, several papers talked about AV1's presence at Oslo Innovation Week. One of the newsworthy points was that Norway's Crown Princess showed an interest in social entrepreneurship and AV1. She used AV1 to talk to one of the chronically ill children, see Figure 3c. A special notice on this was also featured at the website of the Royal House of Norway, showing the photo of the princess with AV1.

\subsubsection{Critical Voices}

Although much fewer in numbers (only 7 out of 170), the articles with more critical voices helped to create other imaginaries. They expressed opinions that AV1's does not act as an enabler of social connectedness, cannot satisfy demands for education or that it presents privacy risks. As can be seen from Table 2, apart from one, these imaginaries appeared only post-commercialization, and represent the change in perception of AV1.
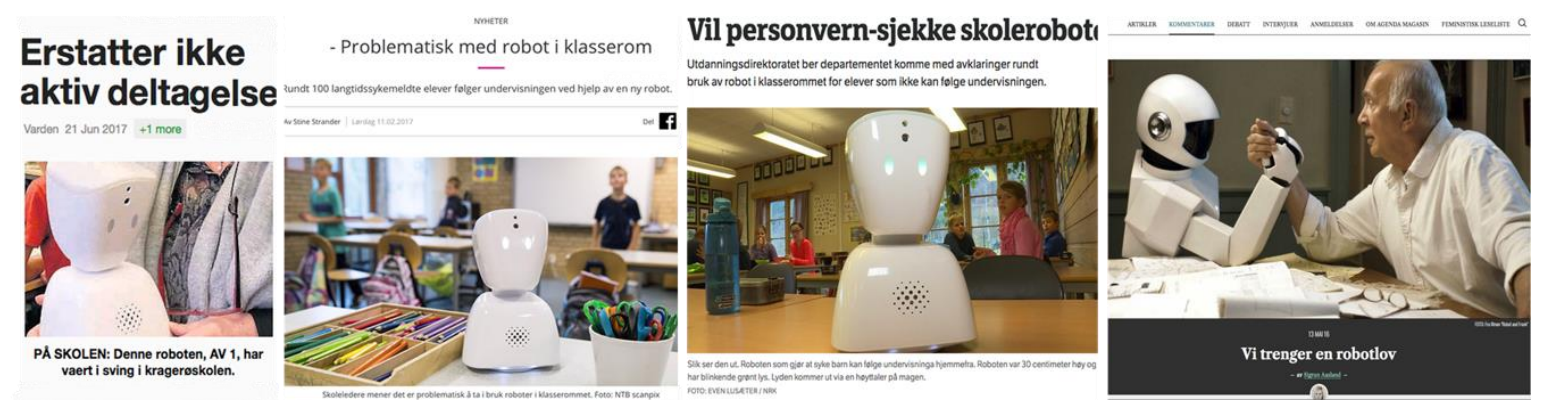

Figure 4. a) News article "Does not replace active participation" 11 , b) article "It is problematic with a robot in the classroom" $"$, c) news article "Will school robots be checked for privacy"13, d) article "We need a robot law"14

One of the national newspapers published an article arguing that AV1 is not an optimal alternative for person-to-person contacts. The article also forwards the view that attending school through AV1 cannot give its users the education they need after long-term absence from school due to their illness: "A robot cannot replace or compensate for physically meeting teachers and schoolmates. If this is seen as a reasonable solution for facilitating teaching and attending to the student's demands for education, it becomes difficult to support such a technological development and cheer on the robot into the classroom" "11.

Another article was more balanced in the discussion of AV1, concluding with "[The presence through the robot] is far worse than being physically socially present, but certainly a little bit better than being entirely absent" 14 .

In 2017, a national newspaper article with a headline "Problematic with a robot in the classroom" 12 was published, see Figure 4b. The article states that several schools contacted the Norwegian Data Protection Authority (DPA) because they were uncertain whether the robot in the classroom violates the Personal Data Act. The article states that one of the things that these schools fear is that someone can see what is happening in the classroom. The long-term ill child or youth are expected to have the access, but there is no way for the school to ensure that others are not having access to AV1 and, thus, the classroom. The article provides a reply from the DPA stating that the robots constitute a privacy risk, and schools must find out what risks they can accept, and whether there are measures that reduce the risks.

Another local newspaper, with a headline: "Should we allow video surveillance in Norwegian schools?" 15 writes: "I saw the television advertisement for the robot that is supposed to attend classes at school as a

\footnotetext{
${ }^{11}$ At https://www.pressreader.com/norway/varden/20170621/281874413403873

${ }_{12}$ At https://www.p4.no/nyheter/--problematisk-med-robot-i-klasserom/artikkel/689010/

13 At https://www.nrk.no/sorlandet/vil-personvern-sjekke-skoleroboter-1.13327572

${ }^{14}$ At https://agendamagasin.no/kommentarer/vi-trenger-en-robotlov/

${ }^{15}$ At https://www.dagbladet.no/kultur/skal-vi-tillate-videoovervaking-i-norske-skoler/66922647
} 
substitute for students with long-term absence. Had the date been April 1, I would clearly consider this as an April fool's joke. But oh, no! It turns out that the robots have infiltrated Norwegian classrooms, long before schools, school professionals, trade unions, county governors and others who should have a principled attitude to the matter have managed to do anything " 15 .

In addition, the article questions the motives of the SE: "I see that the forces behind this invention are pushing a long-term ill or disabled child in front of them in the debate about whether school surveillance should be allowed or not. So, instead, parents and teachers who see this madness will get the 'blame' and appear as heartless $" 15$.

\subsubsection{Economic and Governance Challenges}

Initially, some of the participants' parents in our study (who received AV1 for free, and got to keep the research product until it became commercially available) stood out in the press and told their positive experiences with the artefact, but also expressed concerns about pricing and their desire for AV1 to be easily available and affordable for all others, when it becomes commercial. This imaginary became something that influenced the startup to change their planned business model and lower the price of the commercial product.

After privacy issues related to the use of the robot in schools were presented in news articles, politicians came forth in the press stating that the government had started a formal process of reviewing the use of AV1 at schools, see Figure 4c. Following this process schools were given legal guidelines regarding how to use AV1 while adhering to privacy laws.

The media's discourse, presenting AV1 as either an aid for education or a wellbeing artefact, influenced later decisions at the governance level regarding who regulates the use of the robots, the Ministry of Education and Research or the Ministry of Health and Care Services. The process of regulating AV1 was difficult and time-consuming, and still ongoing, since different legal paragraphs apply for educational tools and wellbeing ones. As the product that can support both education and wellbeing, AV1 falls between these governance bodies and their different regulations.

\section{DISCUSSION}

We found that the positive imaginaries, especially at the start of our research, created more opportunities for field engagement of AV1. The media coverage made AV1 broadly familiar and people curious about the research product, creating willingness to engage in discussions about this new technology. The more critical views, on the other hand, affected both our research and No Isolation more directly, e.g., prompting re-thinking of the SE's business model (see 3.2.4) and bringing forth ethical aspects regarding our research. Exemplifying the latter, we point to the privacy issues regarding the parents of our participants, or others who could use the robot to observe the classroom. This led to asking the parents to sign a formal document attesting that only the participant would use the robot to participate in classroom activities. The parents signed the document after discussing privacy and concerns that classmates' parents had, in line with the media. Although we do not discuss design implications in this paper, we wish to mention that to protect the privacy needs of classmates, we suggested that No Isolation installs an off-button in case that sensitive situations in the classroom emerge and that AV1 needs to be turned off.

We ongoingly made critical and ethical judgments to protect our participants' identities from the media. However, some of our participants and their families decided to come forward and engage with the media on their own, seeing it as an opportunity to bring attention to health issues and other needs. Similar to (Gaver et al. 2010), we found out that researchers cannot protect the participants from the implications of the visibility given by the media. It was easy to understand that the visibility could be appealing and provide some relief from the feeling of being forgotten. Sometimes, the effects of appearing in the media were positive. However, researchers need to be sensitive to such appearances and discuss the implications before the media attention.

\subsection{Discourse Analysis Findings}

Initial media coverage was exclusively positive, with exception of the one balanced article that was published during the first year. This overly positive coverage is in line with results from previous research on $\mathrm{HCI}$ in the media, see Vines et al. (2017). The robot shape of AV1, see Culén et al. (2019), was perceived as cool by 
adolescents at the risk of isolation, and this alone easily made their expectations high. Together, positive press and high expectations did influence the participants in our research. On the other hand, a more critical view of AV1 as a hindrance to person-to-person presence is also skewed, and misses the point of the complex real-life situations of research participants (who do not have a choice to engage in person due to their illness). For participants in our research, the choice was often between AV1 or no presence at all. Looking critically at the media coverage, it mirrors difficulties when working with complex social issues and socio-cultural problem-solving, risking over-simplification and being overly optimistic.

Criticality (not criticism) is an important part of research that aims to reveal the unintended consequences of new technological products for the real world. Thus, the points of criticism that the media coverage brought up in post-commercialization phase were not new for us. We were already acutely aware of challenges with AV1 in everyday lives of our users. For instance, from the start of the research project privacy was a key concern for both researchers, participants, and for No Isolation. In the course of the research nuanced perspectives regarding AV1 and privacy emerged, but remained invisible in media coverage that focused only on the 'peephole' aspect of AV1's streaming.

When we chose to look for imaginaries created through the media coverage, we also hoped to find some clues regarding the Collingridge's dilemma. More specifically, we were curious if the public portrayal of the research and social innovation focus of AV1, would allow us to gain early knowledge on how the research product affects the society. The indications of social implications could then be used to inform the design as a step towards doing responsible innovation. This seemed relevant to explore especially in light of research collaborations with SE, and seeing how commercial products are too often first launched and then later the social implications investigated. However, from sixty-two news articles from the pre-commercialization stage, only one article had a more balanced view regarding the social presence through AV1 ${ }^{14}$. Seeing how the first year of media attention projected high levels of technological determinism, it did not reveal real-world implications of the technology. When more critical voices appeared, the product was already a commercial one. Thus, the window for the media attention to facilitate responsible innovation through early research inputs on social implications was already closed, with one exception, related to the economic challenges for users that surfaced in the second year and that actually brought about changes in the SE's business model.

However, we remain hopeful that for the future products, a combination with ethical research, social innovation and media coverage could yield a better insight into the implications of new technologies.

\subsection{Implications and Opportunities from Media Interest on Research}

The media influenced the study participants and others related to the project, such as school principals and teachers, so it is reasonable to ask if it did influence us as researchers, leading to biased research. Additionally, collaboration with SE, in part because of the media coverage could also lead to biased research. Being aware of this, we made a contract with No Isolation regarding independence of our research, and sent the contract for approval to the Ethical Review Board, which subsequently was approved. No Isolation and its marketing, advertising, and fundraising were entirely separated from the research. On the other hand, in line with (Chilana, et al., 2015b), we found out that, even though there are challenges, collaboration between researchers and social entrepreneurship offers a huge opportunity to increase the visibility of research and design at large, perhaps also opening different research paths from the traditional research related to technology deployment and acceptance.

At the beginning of the study, people found robots placed in classrooms to provide sick adolescents and children with a remote social presence closer to science fiction than reality. The media publicity did make it easier for people to relate to this new technology, which in turn, affect our field work positively. The perceived newness of the technology was initially a barrier when talking to people about its real-world social implications. However, after the massive media attention, the robot became a frequent topic of conversations everywhere, making the entire society familiar with the product, reducing the novelty and perceived strangeness of the technology.

The pre-commercialization media attention and the public engagement that followed, got also those with governance and political decision-making power involved. Drawing in such stakeholders may be one of the most essential aspects when doing social innovation design work. The illness has made the participants in our research belong to a socially vulnerable group at risks of isolation and reduced access to education, among others. These issues are a matter of social governance, decisions made by such stakeholders have a power to 
influence participants' social worlds. For instance, new laws and regulations need to be made for the commercial version of the research product to be legal to use at schools - for the reasons of privacy protection. The legal issue is not that the current privacy laws forbid the use of AV1, but that AV1 represents a new technology, and as such, it is not covered by existing privacy laws regulating the use of technology at schools.

Finally, although these are initial steps in looking into the social innovation and collaborations with research products with SE, we find that the media engagement had impact and potentially, can be a way to engage with the social implications of new technology artefacts to facilitate responsible innovation.

\section{CONCLUSION}

This paper argued that research products in collaboration with SE could be potentially a useful and novel approach to improving and transforming innovation outcomes before they become real-world products, that is, research products intended for commercialization can be a way of engaging with the social implications of new technology artefacts and facilitate responsible innovation. Our research, as a consequence of the collaboration with the SE startup received a considerable amount of media attention. Our findings regarding the influence of the media attention show that AV1 became familiar to the broad public, raising the curiosity about the robot and facilitating our access to schools as part of the field work. In general, people could easily make up their minds about how they experience or think about AV1, helping us to access and explore the social, cultural and ethical impacts of this new technology design artefact before and just after commercialization.

Using discourse analysis to explore the way that media addressed AV1, we identified imaginaries related to social connectedness, social entrepreneurship and gender equality as positive social impacts. Also, the critical voices influenced large groups of people and raised concerns regarding the quality of education through the robot, the quality of social contacts, privacy risks, and economic and governance challenges around AV1. The critical voices had substantial impact, for example, by influencing politicians and policymakers to make changes in guidelines and regulations regarding AV1. Moreover, media coverage allowed for public discourse beyond our own research on how AV1 as a commercial product could affect its users and the society at large.

\section{ACKNOWLEDGEMENT}

No Isolation has our sincere gratitude for a wonderful collaboration and for the opportunity to engage in HCI research with AV1 as a research product intended for commercialization and as social innovation.

\section{REFERENCES}

Auger, J. (2013). Speculative design: crafting the speculation. Digital Creativity, 24(1), 11-35.

Børsting, J., \& Culén, A. L. (2017). Experiences with a Research Product: A Robot Avatar for Chronically Ill Adolescents. In T. Issa, P. Kommers, T. Issa, P. Isaías, \& T. B. Issa (Eds.), Smart Technology Applications in Business Environments (pp. 159-183). Hershey: PA: IGI Global.

Chatting, D., Kirk, D. S., Durrant, A. C., Elsden, C., Yurman, P., \& Bichard, J. A. (2017). Making Ritual Machines: The Mobile Phone as a Networked Material for Research Products. Proceedings of the 2017 CHI Conference on Human Factors in Computing Systems, 435-447.

Chilana, P. K., Czerwinski, M. P., Grossman, T., Harrison, C., Kumar, R., Parikh, T. S., \& Zhai, S. (2015a). Technology Transfer of HCI Research Innovations: Challenges and Opportunities. Proceedings of the 33rd Annual ACM Conference Extended Abstracts on Human Factors in Computing Systems - CHI EA'15, 823-828.

Chilana, P. K., Ko, A. J., \& Wobbrock, J. (2015b). From User-Centered to Adoption-Centered Design: A Case Study of an HCI Research Innovation Becoming a Product. Proceedings of the 33rd Annual ACM Conference on Human Factors in Computing Systems - CHI '15, 1749-1758.

Collingridge, D. (1980). The social control of technology. New York: St. Martin.

Culén, A. L., Børsting, J., \& Odom, W. (2019). Mediating Relatedness for Adolescents with ME: Reducing Isolation through Minimal Interactions with a Robot Avatar. Proceedings of the 2019 ACM Conference on Designing Interactive Systems (DIS '19). https://doi.org/10.1145/3322276.3322319. 
Gaver, W. (2012). What should we expect from research through design? Proceedings of the 2012 ACM annual conference on Human Factors in Computing Systems - CHI '12, 937-946.

Gaver, W., Blythe, M., Boucher, A., Jarvis, N., Bowers, J., \& Wright, P. (2010). The prayer companion: openness and specificity, materiality and spirituality. Proceedings of the 28th international conference on Human factors in computing systems - CHI '10, 2055-2064.

Godin, B. (2015). Innovation Contested: The Idea of Innovation Over the Centuries. London and New York: Routledge.

Grimme, S., Bardzell, J., \& Bardzell, S. (2014). "We've conquered dark": shedding light on empowerment in critical making. Proceedings of the 8th Nordic Conference on Human-Computer Interaction: Fun, Fast, Foundational - NordiCHI '14, 431-440.

Höök, K., Bardzell, J., Bowen, S., Dalsgaard, P., Reeves, S., \& Waern, A. (2015). Framing IxD knowledge. Interactions, 22(6), 32-36.

Isaacs, E. A., Tang, J. C., Foley, J., Johnson, J., Kuchinsky, A., Scholtz, J., \& Bennett, J. (1996). Technology transfer: so much research, so few good products. Conference companion on Human factors in computing systems common ground - CHI '96, 155-156.

Ishii, H. (2008). The tangible user interface and its evolution. Communications of the ACM, 51(6), 32-36.

Jasanoff, S., \& Kim, S.-H. (2015). Dreamscapes of modernity: Sociotechnical imaginaries and the fabrication of power. Chicago, IL: University of Chicago Press.

Koskinen, I., Zimmerman, J., Binder, T., Redstrom, J., \& Wensveen, S. (2011). Design research through practice: From the lab, field, and showroom. Amsterdam, Netherlands: Elsevier.

Kudina, O., \& Verbeek, P.-P. (2018). Ethics from Within: Google Glass, the Collingridge Dilemma, and the Mediated Value of Privacy. Science, Technology, \& Human Values, 44(2), 291-314.

Lindley, J., Coulton, P., \& Sturdee, M. (2017). Implications for Adoption. Proceedings of the 2017 CHI Conference on Human Factors in Computing Systems - CHI '17, 265-277.

Lockton, D., \& Candy, S. (2018). A Vocabulary for Visions in Designing for Transitions. Proceedings of Design Research Society Conference DRS 2018: Catalyst, 908-926.

Lubberink, R., Blok, V., Van Ophem, J., \& Omta, O. (2017). Lessons for Responsible Innovation in the Business Context: A Systematic Literature Review of Responsible, Social and Sustainable Innovation Practices. Sustainability, 9(5), $1-31$.

Odom, W., Wakkary, R., Lim, Y., Desjardins, A., Hengeveld, B., \& Banks, R. (2016). From Research Prototype to Research Product. Proceedings of the 2016 CHI Conference on Human Factors in Computing Systems - CHI '16, 2549-2561.

Pierce, J. (2014). On the presentation and production of design research artifacts in HCI. Proceedings of the 2014 conference on Designing interactive systems - DIS '14, 735-744.

Ratto, M. (2011). Critical Making: Conceptual and Material Studies in Technology and Social Life. The Information Society, 27(4), 252-260.

Ribeiro, B. E., Smith, R. D. J., \& Millar, K. (2017). A Mobilising Concept? Unpacking Academic Representations of Responsible Research and Innovation. Science and Engineering Ethics, 23(1), 81-103.

Stilgoe, J., Owen, R., \& Macnaghten, P. (2013). Developing a framework for responsible innovation. Research Policy, 42 (9), 1568-1580.

Talja, S. (1999). Analyzing Qualitative Interview Data. Library and Information Science Research, 21(4), 459-477.

Tanenbaum, J. G., Williams, A. M., Desjardins, A., \& Tanenbaum, K. (2013). Democratizing technology: pleasure, utility and expressiveness in DIY and maker practice. Proceedings of the SIGCHI Conference on Human Factors in Computing Systems - CHI '13, 2603-2612.

Taylor, C. (2002). Modern Social Imaginaries. Public Culture, 14(1), 91-124.

van der Duin, P. (2018). Toward "Responsible Foresight”: Developing Futures that Enable Matching Future Technologies with Social Demands. World Futures Review, 11(1), 69-79.

Vines, J., McNaney, R., Holden, A., Poliakov, I., Wright, P., \& Olivier, P. (2017). Our Year with the Glass: Expectations, Letdowns and Ethical Dilemmas of Technology Trials with Vulnerable People. Interacting with Computers, 29(1), $27-44$.

Vines, J., Thieme, A., Comber, R., Blythe, M., Wright, P. C., \& Olivier, P. (2013). HCI in the press: online public reactions to mass media portrayals of HCI research. Proceedings of the SIGCHI Conference on Human Factors in Computing Systems - CHI '13, 1873-1882.

Weiser, M. (1993). Some computer science issues in ubiquitous computing. Communications of the ACM, 36(7), 75-84.

Wortham, S. E. F., \& Reyes, A. (2015). Discourse analysis beyond the speech event. London and New York: Routledge.

Zimmerman, J., \& Forlizzi, J. (2014). Research through design in HCI. Ways of Knowing in HCI. New York, NY: Springer. 